\title{
In reply: Calibration of the neuromuscular monitor: Is it necessary?
}

\author{
Sanjay M. Bhananker, MD • Miriam M. Treggiari, MD, MPH, PhD • \\ Stephan R. Thilen, MD, MS
}

Received: 5 November 2015/ Accepted: 10 November 2015/Published online: 14 December 2015

(C) Canadian Anesthesiologists' Society 2015

\section{To the Editor,}

We agree with Dr. Claudius that calibration is an important issue to consider when using the train-of-four (TOF)-Watch ${ }^{\circledR}$ SX monitor. ${ }^{1}$ For the purpose of this study, we decided against calibrating the device. Our main consideration was that it is unlikely that calibration would have affected the results of this study. Without calibration, the TOF-Watch SX uses a stimulating current of $50 \mathrm{~mA}$ and a sensitivity of 157 (the proprietary scale is 1-512) as its default settings. These default values are likely to provide both supramaximal stimulation and appropriate sensitivity for the vast majority of typical adult patients such as those included in our study. Under section 3.11 in the TOF-Watch SX manual cited in our paper, it states, "If the responses of a non-relaxed patient are too small for an accurate measurement, as can be seen in children or when using the orbicularis oculi muscle, then a gain calibration will optimize the sensitivity."2 Our additional consideration to omit calibration was the emphasis on proper positioning of the transducer. If the transducer is slightly misaligned with the thumb trajectory, then a sensitivity adjustment may compensate for this. We have substantial experience with the TOF-Watch SX and made sure that the position of the transducer was optimized. Furthermore, the TOF-Watch monitors are

S. M. Bhananker, MD $(\varangle) \cdot$ S. R. Thilen, MD, MS

Department of Anesthesiology and Pain Medicine, Harborview

Medical Center, Seattle, WA, USA

e-mail:sbhanank@uw.edu

M. M. Treggiari, MD, MPH, $\mathrm{PhD}$

Department of Anesthesiology \& Perioperative Medicine,

Oregon Health \& Science University, Portland, OR, USA often used without calibration in clinical practice. In fact, the device has also been used without calibration in several previous research studies. ${ }^{3,4}$ One such study found that, under certain conditions, the uncalibrated TOF-Watch SX was as reliable as a calibrated device for the purpose of excluding residual paralysis. ${ }^{5}$

Therefore, the possibility that our results would be explained by the lack of calibration is speculative and, in our view, highly unlikely. As discussed in our manuscript, we do not know which is more accurate, the provider TOF count or the TOF-Watch SX count. Nevertheless, we expect that the majority of clinicians will continue to obtain TOF counts by subjective assessment. In addition, it is unlikely that subjective TOF counts have been validated against a measure typically considered more objective based on neuromuscular reversal research. Future research may confirm our suggestion that there is a discrepancy between monitoring modalities, and this should be considered for sugammadex dosing guidelines.

Conflicts of interest None declared.

\section{References}

1. Casper C. Calibration of the neuromuscular monitor: Is it necessary? Can J Anesth 2016; 63: this issue: DOI: 10.1007/ s12630-015-0535-4.

2. TOF-Watch SX Operator Manual, version 33.512/A. Available from URL: http://www.mainlinemedical.com/mm/manuals/ bluestar_tof_watch_sx_user_manual.pdf (accessed November 2015).

3. Murphy GS, Szokol JW, Avram MJ, et al. Intraoperative acceleromyography monitoring reduces symptoms of muscle weakness and improves quality of recovery in the early postoperative period. Anesthesiology 2011; 115: 946-54. 
4. Murphy GS, Szokol JW, Avram MJ, et al. Residual neuromuscular block in the elderly: incidence and clinical implications. Anesthesiology 2015; DOI: 10.1097/ALN.0000000000000865.
5. Schreiber JU, Mucha E, Fuchs-Buder T. Acceleromyography to assess neuromuscular recovery: is calibration before measurement mandatory? Acta Anaesthesiol Scand 2011; 55: 328-31. 